\title{
The Sustainable Development Goals and the Importance of Cultural Change
}

\section{David O' Connor}

Formerly United Nations Division

for Sustainable Development

\section{Abstract}

Sustainable development is an ambition rather than a reality. Profound changes will be needed to achieve it in ways of producing and consuming. These will only happen at scale if societies undergo major cultural changes, including placing greater value on undervalued natural assets and internalizing in individual decisions the costs they impose on the environment, including the climate system. For these changes to occur, societies need to become more equitable, ensuring that all members enjoy decent living standards and are thus willing and able to attach greater weight to the well-being of future generations.

\section{Keywords}

sustainable development, natural assets, biodiversity loss, climate change, intraand intergenerational equity 


\section{Introduction: From incremental to transformative change}

Just over five years ago, the nations of the world together with various civil society representatives began the journey toward the 17 Sustainable Development Goals (SDGs) adopted at a United Nations (UN) Summit in September 2015 as part of the 2030 Agenda for Sustainable Development ("Transforming our World"). The Summit-and the intergovernmental negotiations which led up to it-was a high point in multilateral cooperation. The international community adopted a hugely ambitious agenda ${ }^{1}$ aimed not at completing the unfinished work of poverty eradication targeted by the Millennium Development Goals (MDGs) but going beyond the MDGs in addressing global environmental challenges like climate change, biodiversity loss, and degradation of land and of waters, including the world's oceans.

The SDGs and the 2030 Agenda recognize the interdependencies among the economic, social, and environmental dimensions of development. Freshwater, for example, while understood to be essential to human life and health, is also a renewable environmental resource whose continued availability depends in large part on the conservation in a healthy state of watersheds, rivers, aquifers, groundwater, and other sources which provide that resource. Productive agriculture is essential to feeding the world's population but how we produce food impacts not just the health of soils but human health and the health of the planet, as agriculture and land use change are significant sources of greenhouse gas emissions globally.

\section{The urgency of a course correction}

The 2030 Agenda aims to rectify the historical imbalance in development models which have given overriding importance to material progress as measured by growth of Gross Domestic Product (GDP) with only secondary consideration to social progress (e.g., addressing structural causes of inequality, including gender inequality) and little consideration to the environmental consequences of a growth fixation. China's long and polluting economic boom represents a recent example of the large environmental costs of a "growth first" model; most industrialized and emerging economies followed similar paths in earlier days. Since the mid- $19^{\text {th }}$ century, economic 
growth has been powered in most countries by fossil-fuel-based energy. ${ }^{2}$ Thus, with growth has come an inexorable rise in greenhouse gas emissions. Looking ahead at the next half century, this model is unsustainable if humanity is to avert runaway climate change.

The SDGs and 2030 Agenda were negotiated in parallel with the Paris Agreement on Climate Change, and tackling climate change is at number 13 of the SDGs. ${ }^{3}$ Implementation of these two agreements must proceed in parallel as well since the 2020s are both the Decade of Action and Delivery of the SDGs and the make-or-break decade for reversing the upward trend in greenhouse gas emissions. If global greenhouse gas emissions are not substantially reduced by 2030 , it will be impossible to stay within the mean global temperature rise of $1.5^{\circ} \mathrm{C}$., which is stated in the Paris Agreement. The Intergovernmental Panel on Climate Change (IPCC) documents in some detail the implications for the planet and for various ecosystems of exceeding that threshold. ${ }^{4}$

The post-World War II international economic institutions and rules have strongly supported this "growth first" model. So, for instance, trade rules as enshrined in the General Agreement on Tariffs and Trade (GATT) and the World Trade Organization (WTO) have erected high hurdles for countries wishing to restrict imports based on the production methods used to produce the exports-though exceptions are permissible where trade restrictions or other policies are deemed necessary to protect human, animal, or plant life, or health, or to conserve exhaustible natural resources ("WTO rules and environmental policies"). The WTO has yet to be stress tested by having to adjudicate cases involving measures (e.g., the carbon border adjustment mechanism proposed in the European Union's Green Deal designed to deter "carbon leakage" from European countries governed by strict carbon reduction measures to other countries with more lax carbon emission controls. The concern is that, as capital is mobile, if climate policy in one country or region significantly raises the costs of production, (e.g. in energy-intensive industries), those industries may shrink there with expansion occurring in other countries with more lax policies-and with global emissions staying the same or even rising. 
Given the world trade rules and the challenges these pose for governments' intent on introducing stronger domestic or regional (in the case of the EU) climate policy measures unilaterally, consumer preferences and choices assume outsized importance in influencing global greenhouse gas emissions. That is because, if enough consumers demand, for example, that the products they consume be produced demonstrably with "zero deforestation" or "zero net emissions," those hoping to sell to them have little choice but to meet those demands. The present problem is that not nearly enough consumers demand such products to be able to make a major difference on global greenhouse gas emissions. Confronted with the choice between green products and cheap products, the choice for most will be cheap. This is a rational choice considering the stark inequalities in income within and between countries and the tight budget constraints of low-income consumers everywhere.

Thus, the likelihood of cultural change such that the majority, even the vast majority, of consumers prefer the "green" alternative is closely linked to the diminution of the stark inequalities characterizing many countries.

The SDGs are a uniquely well-suited framework to address the climate change challenge and other environmental challenges because they are a holistic set of goals which also aim to reduce inequalities within and between countries and to address the basic problems of inadequate access to food, health care, education, energy, and economic opportunity of the world's poor (Kamau, Chasek, O’Connor 23). They were not naively conceived without acknowledging possible trade-offs between different goals and targets. Rather, they are presented as a challenge to governments and others not to hide behind trade-offs to explain why we cannot feed the hungry and protect the planet at the same time. They say: maybe not now, given our broken economic model and perverse incentives, but we have to find a new model, change the incentives and behaviors, and develop the technologies and production methods which will permit us, for example, to produce adequate nutritious food for everyone sustainably. This will also involve changing consumers' food preferences, given the sharply different effects of 
different foodstuffs on greenhouse gas emissions, with red meat particularly high in emissions.

The global food system is an excellent example of a system and set of technologies which have the capacity to produce enough food to feed over seven billion people-although hundreds of millions still go hungry-but which has in the process contributed significantly to both health and environmental problems from obesity to eutrophication from nutrient runoff from fields to greenhouse gas emissions. Given the importance of farming and food security politically, governments around the world have heavily subsidized farmers, encouraging them to convert biodiverse ecosystems to monocrop fields, and to overapply water, fertilizer, and chemicals. Thus, incentives have perversely encouraged environmental degradation.

The food system extends to the plate and people's food preferences, and here, too, the system has been environmentally devastating as animal protein consumption rises rapidly with incomes. Such protein consumption requires much larger quantities of land, water, and other inputs than vegetable protein, thus contributing to large-scale land conversion to grow feed grains for livestock. The Food and Agriculture Organization in 2012 estimates that $26 \%$ of the Planet's ice-free land is used for livestock grazing and $33 \%$ of croplands are used for livestock feed production. Thus, an important part of the challenge of transforming food systems is a large-scale change in food consumers' preferences toward less meat-rich diets, a significant cultural change especially in wealthier countries and among wealthier people generally. While various expressions of vegetarianism are becoming more common in developed countries, they represent a small share of total food demand there. Meanwhile, emerging economies are experiencing growing meat demand with rising household incomes. ${ }^{5}$

\section{Sustainable economics}

Renewable energy is one example of a green product which, originally much more expensive than fossil fuels per unit of energy supplied, has dramatically fallen in price to the point where electricity from onshore wind and solar power is cheaper than that from a new combined-cycle gas 
plant-\$40-41 versus \$56 per megawatt hours (MWh) (Roser). This makes renewable-generated electricity ever more affordable even to lower-income households-many of which still lack access to any electricity, particularly in sub-Saharan Africa. The economics of wind and solar power have been driven by economies of scale and learning, accelerated by "market-making" measures like ambitious renewable energy targets and feed-in tariffs such as those introduced in countries like Germany, Denmark, and Spain. Germany's renewable electricity production, in the most recent legislation, is targeted to rise by $55 \%$ in 2030 , with the bulk of the increase coming from solar photovoltaics (PV) and offshore wind (Appun).

It remains to be seen how many other "green" products enjoy comparable scale and learning economies and thus can, with a large enough market, become price-competitive with their traditional competitors. There is certainly a reason to believe that, over time, prices of many such products will fall. For now, and for most low-income consumers, they remain unaffordable (or unattractive, given tight budget constraints) (Chouinard, Ellison, Ridgeway). Electric vehicles (EVs) are a case in point, where their current cost limits their market but the cost of EV batteries is expected to continue to fall, making such cars ever more affordable even without government subsidies (Boudway). 


\section{Electric Vehicle Battery Prices Near \$100/kWh Watershed}

A BloombergNEF survey shows the average price of lithium-ion battery packs at $\$ 137$ per kilowatt-hour. At $\$ 100 / \mathrm{kWh}, \mathrm{EVs}$ are as cheap to make as gas cars.

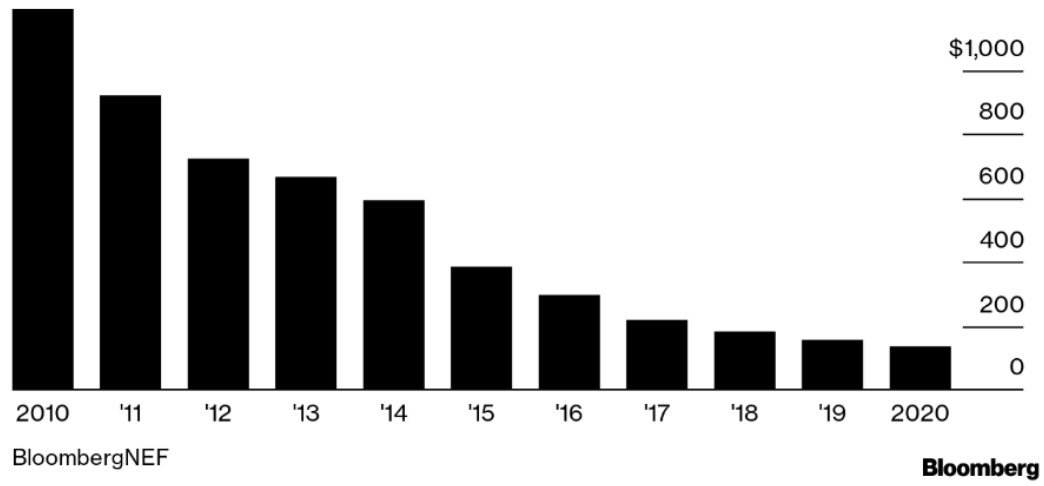

Source: www.bloomberg.com/news/articles/2020-12-16/electric-cars-areabout-to-be-as-cheap-as-gas-powered-models.

As sustainable development and tackling climate change in a timely manner will require a wholesale and rapid shift toward low-emissions, less environmentally damaging products and production methods, it will not suffice to wait for markets alone to lower the costs of such products and to make them competitive with traditional products. Policy inducements will be needed to accelerate the pace. For example, where economies of scale are operative and where government is a large consumer-e.g., with buses and other vehicles, office equipment and supplies, health-care products in many countries, and certain other products-government procurement policy can help to create viable markets for green products like electric buses. Still, procurement policy can only reach so far. The government can also impose tax to polluting products in order for these to be less cost competitive by internalizing the costs of pollution in the price. Such policies work, however, not by lowering the costs of green products, but by raising the 
costs of "brown" ones. In the near term, then, it fails to address the problem of unaffordability of green products.

Far more efficacious to effect the large-scale changes needed in consumption and production patterns would be to introduce redistributive fiscal policy measures aimed at raising the real post-tax incomes of low-income consumers while limiting the same for high-income earners. Cross-country data on energy footprints of households across the income distribution show that high-income households have much larger footprints than low-income ones. Globally, the consumption share of the bottom half of the population is less than $20 \%$ of final energy footprints, which in turn is less than what the top $5 \%$ of the population consumes (Oswald, et al. 231).

Such redistribution would not, on its own, ensure that with rising incomes ordinary households would choose "green" products over traditional ones. Policy-induced relative price changes must also be part of the equation. Moreover, education and awareness-raising will be important complements, to instill in the population an appreciation of the importance of their consumption choices to tackling environmental challenges-and the importance of the latter to their own well-being and that of their children and grandchildren. Also, as there tends to be a strong copycat tendency in areas such as fashion, convincing trendsetters to choose sustainable products can have a demonstration effect on other consumers' preferences.

Given the urgency of tackling a challenge like climate change-in short, the need to overhaul whole sectors of the economy in a short time framewaiting for consumers to change their preferences without any steering or nudging may simply not result in the required pace of change. Governments have a variety of policy instruments at their disposal to complement efforts at shaping consumer values and preferences. Taxes on polluting products are one; limitations or even prohibitions on certain activities and technologies are another; education of people about the personal financial benefits over a product's lifetime of purchasing energy-saving lighting, appliances, or vehicles is a third. Very often, governments will want or need to combine all these instruments to achieve the desired effect at scale and in time. 
One of the biggest challenges in addressing a challenge like biodiversity loss is the failure of markets to reflect accurately the value of nature-e.g., the economic costs of destroying a natural watershed and having to substitute it with investment in a drinking water treatment plant. Those costs may only become evident once the damage has been done, even if it would have been much less costly to protect the watershed and its ecosystem services in the first place. Dasgupta observes that, in addition to nature's mobility (e.g., migrations of many different species):

Many of the processes that shape our natural world are silent and invisible. The soils are a seat of a bewildering number of processes with all three attributes. Taken together the attributes are the reason it is not possible to trace very many of the harms inflicted on Nature (and by extension, on humanity too) to those who are responsible. Just who is responsible for a particular harm is often neither observable nor verifiable. No social mechanism can meet this problem in its entirety, meaning that no institution can be devised to enforce socially responsible conduct. (5)

The absence or imperfect functioning of markets for ecosystem services means private individuals and corporations have little or no incentive to conserve the natural assets which support those services. ${ }^{6}$ The risk of degradation or collapse can exist even for products which are traded in markets, like fish, but which depend on the health of an open access natural resource (like coastal or offshore waters and ecosystems like coral reefs). Various fish species' reproduction rates risk being exceeded by their extraction rates from overfishing. Governments and fisher communities have developed ways to manage fisheries to ensure timely replenishment of fish stocks (Asche, et al. 11221) but these practices remain underutilized. Illegal, unreported, and unregulated (IUU) fishing remains a serious global problem, ${ }^{7}$ as countries with large marine territories often lack the capacity to police them effectively and as monitoring and reporting of high seas fishing are inadequate.

\section{International equity in pursuing sustainable development}

Environmental challenges today transcend national borders yet, national sovereignty remains very much the bedrock of international law enshrined 
in the United Nations Charter. This requires international cooperation among sovereign states to tackle challenges like climate change, governance of the high seas, and conservation of biodiversity. All three problems are thus the subject of international treaties, or conventions, negotiated under the auspices of the United Nations. Of course, most biodiversity resides within national borders, but the benefits of a biodiverse planet and of a stable climate system accrue to all of humanity. Thus, all nations have an interest to ensure adequate conservation of biodiversity and stabilization of the climate system, which will depend not only on their own actions but on those of other State, private and civil society actors.

Two problems plague efforts to forge stronger international cooperation: the costs and benefits of action are not equally shared across countries; and countries differ markedly in their financial and other means to take action.

First is the problem in the distribution of costs and benefits. In the case of climate change, 20 countries account for almost $80 \%$ of global emissions today. ${ }^{8}$ Meanwhile, the benefits of action to slow and then halt climate change accrue to many countries, in the first instance to small-island developing States (SIDS), low-lying countries and other countries particularly exposed to extreme weather events. Of the 30 countries ranked most vulnerable $^{9}$ to climate change, 23 are low-income countries. Yet, whatever these countries might do to lower their own emissions, it will have a negligible impact on the problem. Thus, the big 20 emitters must be convinced to take bold action. Some of those are lower-middle income countries-notably India-which still have major development challenges to address, not least ending extreme poverty, and therefore only reluctantly would forego use of cheap coal reserves for electricity generation. Global transfers can help address these concerns, though mobilizing international climate finance on a sufficient scale remains problematic. Developed country delivery of multilateral commitments on climate finance will be a high priority at the $26^{\text {th }}$ Conference of the Parties to the UN Framework Convention on Climate Change, taking place in Glasgow in November of 2021. 
In relation to biodiversity, countries rich in biodiversity are relatively few, with 17 countries accounting for roughly 70\% of the Earth's biodiversity ${ }^{10}$ and only eight of these are the same as those accounting for the bulk of greenhouse gas emissions. Some of these countries are low-income; others are lower-middle-income. If they are to be expected to conserve the biodiversity within their borders for the benefit of humanity, they can reasonably expect adequate remuneration for conserving these valuable natural assets. Yet, until now, the resource flows for this purpose have generally not been equal to the opportunity costs of conservation, namely, foregoing the conversion of lands to other uses-harvesting timber, planting palm oil or soybean, or raising cattle. The negotiations currently underway under the auspices of the Convention on Biological Diversity (CBD) on a post2020 global biodiversity framework include the matter of global financing for biodiversity conservation; the financing gap has recently been estimated at $\$ 711$ billion per year ("Financing Nature"). ${ }^{11}$ There is little prospect for this gap to be closed by public funds alone which suggests that ways must be found to tap into the huge pools of financial capital controlled by private investors, notably institutional investors like pension funds and sovereign wealth funds. Climate finance has a greater prospect of attracting significant private money insofar as it goes to commercially viable renewable energy or electric rail or other projects, but so far multilateral financial institutions like the World Bank have had limited success in tapping institutional investor capital. ${ }^{12}$ Biodiversity finance has had even less success tapping into private finance on a significant scale beyond philanthropies, though the Global Environment Facility does mobilize biodiversity finance largely from governments. Ironically, tackling climate change may be the best hope for increasing biodiversity-relevant finance, as so-called "nature-based solutions" (NBS) like forest restoration, avoided deforestation, mangrove replanting, and restoration of degraded lands, enjoy wider adoption as part of the greenhouse gas mitigation arsenal. These investments have along the added benefit of often being beneficial for climate change adaptation-e.g., with mangroves as buffers against storm surges and coastal erosion, forest 
cover mitigating erosion on sloping lands-and conservation of vital ecosystem services like water flow regulation and purification.

Second, countries differ greatly in their financial and technical capacities to address global challenges like climate change and biodiversity loss. Separate from the question of an equitable or fair sharing of the costs of action-e.g., measures taken by a mega-diverse country to conserve its biodiversity or greenhouse gas mitigation measures taken by a low-income country-is the question of ability to pay. Indonesia and the Democratic Republic of Congo (DRC), for example, are both biodiversity-rich countries, yet, based on World Bank data, Indonesia's per capita income is around \$4,000 and DRC's is around $\$ 500$. Meanwhile, per capita income in the United States, another mega-diverse country (according to the World Conservation Monitoring Centre) is roughly $\$ 66,000$. So, clearly the capacity to finance biodiversity-related investments from domestic resources differs markedly across countries rich in biodiversity. International development finance is meant to be one means of addressing inequities in ability to pay but aid budgets are constrained by the extent of domestic political support and are therefore not scaled to match recipient country needs whether for biodiversity conservation or for other purposes.

\section{Conclusion: A way forward toward greater global solidarity}

International financial flows to developing countries which contribute to providing international public goods like climate stabilization and biodiversity conservation remain below what is needed, though estimates of the funding gap vary..$^{13}$ For instance, climate change mitigation investment needs in developing countries from various sources (the International Energy Agency, McKinsey, and the United Nations Framework Convention on Climate Change, the International Institute for Applied Systems Analysis) range between \$180-540 billion per year between 2010 and 2030 (Fankhauser, et al. 203). The scale of international financial flows to developing countries from multiple sources will need to increase significantly if we are to come to grips with these challenges. For low-income countries, 
concessional development finance will have to constitute the largest share, at least initially.

If at present domestic political constituencies in major donor countries do not render likely a sizeable increase in development assistance to financial global public goods like climate stabilization and biodiversity conservation, then the best hope is that future generations-beginning with the current generation of young people-will become a powerful political constituency in the coming years, supporting stronger domestic action and global solidarity to tackle these global challenges. This can happen and may even be likely to happen as young people are not only acutely aware of climate change (if not to the same extent biodiversity loss) but many are also active in pressuring their governments for more ambition to address it. The Swedish teenage climate activist, Greta Thunberg, has inspired and led the emergence of a global youth movement for stronger climate action. Another factor, based on the above discussion, may be what happens to domestic inequalities in some of the large donor countries. Admittedly, there is not a close inverse relationship between the degree of income inequality in a country and the share of its gross national income (GNI) which it devotes to development assistance. For instance, the USA and the United Kingdom are two of the most unequal high-income OECD countries (as measured by their Gini coefficients), yet the UK devotes a sizeable share of its GNI to development assistance (0.70\%) while the United States devotes $0.18 \%$ (though in absolute dollar amount it is the largest single donor because of the size of its GNI). ${ }^{14}$

It is at least plausible that, within a given country's domestic cultural milieu, reducing the degree of domestic income inequality-and the poverty rate-would make the political case for increasing international development assistance more palatable. If so, then redressing domestic inequalities should provide favorable conditions for a country's taking action to increased official development finance, including to support low-income and lower-middle-income countries' climate and biodiversity finance needs.

Beyond financing, global solidarity can and does take other forms. International scientific and technological cooperation is crucial for tackling climate change, conserving biodiversity, and early detecting and responding 
to pandemic outbreaks such as COVID-19. Such collaboration is facilitated by international education, student, and faculty exchange. While scientific research increasingly requires international collaboration, collaboration faces several barriers which need to be addressed. ${ }^{15}$

Ultimately, such global solidarity can be greatly facilitated by a cultural shift, one which seems possible if not already materializing in the younger generation. The shift, which has been enabled by the internet and information technologies, involves self-identification not only as a citizen of a particular country but as a global citizen. This implies assuming the responsibilities of global citizenship-not only respect for human rights irrespective of country but also recognition of the need for all people everywhere to bear their fair share of the burden of action to solve global challenges like climate change and biodiversity loss while also addressing persistent problems of poverty and hunger, as called for in the Sustainable Development Goals. These goals are embedded in a unified, integrated agenda, one for the cooperative attainment and the shared well-being of all humankind. 


\section{Notes}

1. Unlike the first 6 MDGs, MDG 7 is couched in very broad terms: "Ensure environmental sustainability" and the targets lack coherence. Climate change figures only in an indicator under target 7.A. The links between environmental health and human well-being are not explicitly reflected in the set of goals and targets.

2. For more information, you may access this chart at ourworldindata.org/ fossil-fuels.

3. Details of the Paris Agreement may be accessed on this site: unfccc.int/ process-and-meetings/the-paris-agreement/the-paris-agreement.

4. Details of the IPCC Special Report on Global Warming may be accessed on this site: www.ipcc.ch/sr15/.

5. For an animation showing the strong correlation between per capita income and per capita meat consumption, visit: ourworldindata.org/ meat-production\#meat-consumption-tends-to-rise-as-we-get-richer.

6. For more information, kindly visit this site: www.paulsoninstitute.org/ key-initiatives/financing-nature-report/.

7. In 2016, the Office of the Director of National Intelligence reported that $15-30 \%$ of global annual catches account for IUU fishing.

8. The 20 by emissions share are China, USA, India, Russian Federation, Japan, Germany, Islamic Republic of Iran, South Korea, Saudi Arabia, Indonesia, Canada, Mexico, South Africa, Brazil, Turkey, Australia, France, Italy, Poland, United Kingdom; see www.ucsusa.org/resources/each-countrys-share-co2-emissions.

9. See this Notre Dame University ranking: gain.nd.edu/our-work/country-index/ rankings/.

10. The 17 megadiverse countries, as identified by the World Conservation Monitoring Centre of UNEP are: Australia, Brazil, China, Colombia, Ecuador, United States, Philippines, India, Indonesia, Madagascar, Malaysia, Mexico, Papua New Guinea, Peru, Democratic Republic of Congo, South Africa and Venezuela.

11. That report puts estimated financial flows into global biodiversity conservation in 2019 between US\$124 billion and US\$143 billion, which is a near-tripling since 2012. Nevertheless, this amount pales in comparison with spending on agricultural, forestry, and fisheries subsidies that degrade nature and are estimated to be at least two to four times greater. The gap estimate includes the additional investments in cropland and rangeland around the world to make their management supportive of biodiversity conservation.

12. For a discussion of why multilateral financial institutions have not succeeded in tapping institutional investment to support climate-aligned investment and how to change that, see OECD (2021). 
13. For the biodiversity financing gap, see Financing Nature, www.paulsoninstitute.org/key-initiatives/financing-nature-report/.

14. See the OECD DAC data: www.oecd.org/dac/financing-sustainable-developme $\mathrm{nt} /$ development-finance-data/.

15. K.R.W. Matthews et al. (2020), International scientific collaborative activities and barriers to them in eight societies, Accountability in Research: Policies and Quality Assurance, Volume 27, 2020, Issue 8. Among the barriers are lack of funding for international work, restrictions on material and data sharing, and differences in academic standards. Respondents also complained about bias against scholars from emerging or developing countries; tandfonline.com/doi/ full/10.1080/08989621.2020.1774373. 


\section{Works Cited}

Appun, Kerstine. What's new in Germany's Renewable Energy Act 2021, 23 April 2021, www.cleanenergywire.org/factsheets/whats-new-germanys-renewable-energy-act-2021. Accessed 30 June 2021.

Asche, Frank, et al. "Three pillars of sustainability in fisheries.” PNAS, 115 (44), 2018, pp. 11221-11225.

Boudway, Ira. Batteries For Electric Cars Speed Toward a Tipping Point, 16 Dec. 2020, www.bloomberg.com/news/articles/2020-12-16/electric-cars-are-about-tobe-as-cheap-as-gas-powered-models. Accessed 30 June 2021.

Chouinard, Yvon, et al. The Sustainable Economy, Oct. 2011, hbr.org/2011/10/ the-sustainable-economy. Accessed 30 June 2021.

Dasgupta, Partha. The Economics of Biodiversity: The Dasgupta Review. Abridged Version, HM Treasury, 2021.

Fankhauser, Sam, et al. "Where are the gaps in climate finance?" Climate and Development, 8 (3), 2016, pp. 203-206, www.tandfonline.com/doi/abs/10.1080/1756 5529.2015.1064811.

Food and Agriculture Organization of the United Nations. Livestock and Landscapes, 2012, www.fao.org/3/ar591e/ar591e.pdf. Accessed 30 June 2021.

Kamau, Macaria, et al. Transforming Multilateral Diplomacy: The Inside Story of the Sustainable Development Goals, Routledge, 2018.

Oswald, Yannick, et al. Large inequality in international and intranational energy footprints between income groups and across consumption categories. Nature Energy, 5, 2020, pp. 231-239.

Paulson Institute. Financing Nature: Closing the Global Biodiversity Financial Gap, 2020, www.paulsoninstitute.org/key-initiatives/financing-nature-report/. Accessed 1 July 2021.

Roser, Max. Why did renewables become so cheap so fast? And what can we do to use this global opportunity for green growth? 02 December 2020, ourworldindata.org/ cheap-renewables-growth. Accessed 30 June 2021.

United Nations General Assembly. Transforming our world: The 2030 agenda for sustainable development. United Nations, 2015, sdgs.un.org/2030agenda. Accessed 30 June 2021.

---. Sustainable Development Report Plan, 2018, sustainabledevelopment.un.org/ content/documents/24797GSDR_report_2019.pdf. Accessed 30 June 2021.

World Trade Organization. WTO rules and environmental policies: GATT exceptions. World Trade Organization, n.d, www.wto.org/english/tratop_e/ envir_e/envt_rules_exceptions_e.htm. Accessed 30 June 2021. 